\title{
CLINICAL AND PATHOLOGICAL REPORT OF A CASE OF ADDISON'S DISEASE WITH TERMINAL MENTAL SYMPTOMS. ${ }^{1}$
}

By HARRY W. MILLER, M. B. (Tor.),

Pathologist and Assistant Physician, Taunton Insane Hospital, Taunton, Mass.

The following case of Addison's Disease with a psychosis which appears to have more than a casual relationship to the somatic disorder is not without interest from a clinical and pathological standpoint in view of the infrequency with which such combinations are observed:

Summary of clinical history.-Female; forty-seven years of age on admission to Taunton Insane Hospital June 30, 1902. No psychopathic taint in the family. Three sisters died of pulmonary tuberculosis. Cotton weaver by occupation; no school education. Is said to have always been robust and vigorous; normal weight $I 50$ to $I 60$ pounds. Twice married, but had no children and no miscarriages. No venereal disorders. A moderate beer drinker.

In the spring of 1900 she began to complain of weakness, exhaustion, and shortness of breath on exertion. "I feel as if I had been working for a year and had no rest. . . . I am so tired and worn-out all the time." Two months later patches of yellow appeared on her face and neck, which were spoken of at the time as "yellow jaundice." The discoloration next appeared on back of the hands, forearms, and the chest. In the fall of 1900 this pigmentation was noticeable, according to the husband, over the greater part of the body. While at first yellowish it later took on a brownish hue, and reached its maximum intensity one year before admission and after that paled somewhat. She was compelled to give up her mill work and engage in a lighter occupation in the summer of 1900. She lost weight, feeling of exhaustion

\footnotetext{
${ }^{2}$ Read at the sixty-second annual meeting of the American MedicoPsychological Association, Boston, June 12-15, 1906.
} 
3IO ADDISON'S DISEASE WITH TERMINAL MENTAL SYMPTOMS [Jan.

increased, and she had frequent dizzy spells and attacks of palpitation of the heart. Her appetite became poor, but there is no history of nausea or vomiting. Throughout IgOI she was only able to take care of her own room as she was unable to withstand the exertion of outside work.

In December, 1901, she became forgetful and discouraged. Her worries were confined chiefly to her physical condition. Beyond this despondency and the forgetfulness no mental symptoms were noted until early in May, 1902, eight weeks before admission, when she told her husband that mice were crawling over her. Paræsthetic sensations were frequently discovered after this. Animals, she said, were crawling upon her. At one time she screamed, saying a dog had bitten her on the arm. Again a search-light was being played upon her back from the neighbor's house. She reacted to this by complaining to the police demanding an investigation, thinking the neighbors were attempting to kill her by means of the search-light.

She did not consult a physician until two weeks before admission. The physicians at the dispensary told her husband that she always talked in a rambling way and was mentally irresponsible, and advised her commitment to the hospital.

Physical summary.-A poorly-nourished, exhausted-looking woman; forty-seven years of age; weight 9I pounds; height 5 feet $2 \frac{1}{2}$ inches. There is a diffuse darkish brown pigmentation over the body, being especially prominent around the nipples, in the axillæ, over the abdomen, on the back of the hands and the extensor surface of the forearms. The color in this latter location is similar to a deep tan, and there is a rather sharp line of demarcation marking off the upper half of the arm where the discoloration is slight (resembles the arm of one who has had their sleeves rolled up, and had the exposed part deeply tanned). The palms of the hands and soles of the feet are not discolored, nor is there any discoloration of the nails of the fingers or toes. On the face, legs, and back the color is less intense than elsewhere. There is a small, irregular patch just above the right breast where the skin is unusually white and somewhat atrophiclooking (leukoderma?). Conjunctivæ pale and clear. Respiration 18 ; pulse 76 , weak and thready; increased on slight exertion. Heart sounds weak but with no murmurs. Heart dulness within 
normal limits. Bowels constipated; urine shows nothing of significance. There is a decided feeling of exhaustion. Facial muscles and lips tremulous. Right pupil a little larger than the left but both react to light and accommodation and consensually. Speech is a little slow and labored with a suggestion at times of slurring. No significant disturbance of the reflexes. No areas of anesthesia or paresthesia can be discovered, but the mental state prevents an accurate examination of sensation.

Summary of mental condition.-Her facial expression is one of indifference and apathy rather than one of depression or anxiety. She is always very quiet and her manner clearly indicates that she prefers not to be interfered with. She is content to remain in bed, does not ask for any attention, and accepts what is done for her without comment. She shows very little animation. While showing some annoyance at intrusions she never gives expression to her irritability in words, nor does she ever display any emotional outbreaks. She never introduces conversation. Her reaction to questions is variable; at times she responds, again the stimulus produces no reaction, and she has to be aroused by a sharp tone before a response can be elicited, and then it is accompanied by a sense of effort. This reaction becomes intensified the longer the examination is continued. Her education is so limited that the usual fatigue tests are impossible, but in many ways the diminution of the capacity for mental application is demonstrated. Her attention is sometimes easily attracted, but in this regard she varies. She is rather more alert at the beginning of the examination, but later she shows a greater sense of effort in responding. Her attention is never distracted by outside occurrences, and the answers she gives are always relevant. She is always able to orient herself for place; sometimes gives the correct day and date, and again says that she cannot think what day it is. She has never been able to give the names of the different physicians or of the nurses though she had been frequently told, and it is impossible for her to describe any of the physicians who at the time of the interview are absent. It is difficult for her to give correctly the events of her life. She has made several contradictory statements regarding them at different interviews, but if sufficiently stimulated she is able to give the correct responses. An accurate analysis of her recent 
312 ADDISON'S DISEASE WITH TERMINAL MENTAL SYMPTOMS [Jan.

memory is likewise rendered difficult, but there is an evident inability to hold in her memory all recent events, and at no interview could she give correctly events in sequence. She is unable to read. Her school knowledge is practically nil, and her general intelligence of a low order so that a just estimate of her intelligence can hardly be given. She has never related any delirious experiences. No sensory hallucinations have been detected here. She does not recall those described in the history, in fact she denies that she ever had any such sensations.

She remained in bed until July I I, but shortly after being allowed to sit up she had a chill and was accordingly returned to bed. Her temperature, which up to this time had remained between $98^{\circ}$ and $99^{\circ} \mathrm{F}$., following the chill rose to $100^{\circ} \mathrm{F}$., but the next day returned to normal.

July 18 she vomited for the first time though previously was nauseated at times. Her appetite was poor. Bowels constipated, an enema being required every second day. At no time was there any diarrhea. Body temperature did not again become elevated; extremities always cold; asthenia profound throughout. Death occurred July $2 \mathrm{I}$ in an attack of syncope.

Autopsy report.-The autopsy was performed seventeen hours after death. Female body, apparently about forty-five years of age ; $158 \mathrm{~cm}$. long. Much emaciation; eyes sunken; rigor mortis present; pupils equally dilated; no odema. The pigmentation is present in the locations noted in the physical examination. No areas of bronzing discoverable on the tongue, mucous membranes of the mouth or vagina.

Thorax.-The left lung presents old adhesions at apex and over lateral surface. No effusion. Right lung free.

Heart.-Pericardial sac free from fluid; no adhesions; no inflammatory changes. Weight, 163 gms.; very small; slight amount of yellowish fat on the surface; right ventricle with a trivial amount of dark clot. Valves normal except aortic, one segment of which shows a pin-head-sized fenestration. Aortic intima smooth without evidence of sclerotic change. Right ventricle, 2 to $4 \mathrm{~mm}$. ; left ventricle, 6 to $10 \mathrm{~mm}$.; aortic valves, 7.5 $\mathrm{cm}$.; mitral valves, $8.5 \mathrm{~cm}$.; tricuspid valves, $9 \mathrm{~cm}$.; pulmonary valves, $6.8 \mathrm{~cm}$. Endocardium and myocardium show nothing in the gross. 
Lungs.-Right, 382 gms.; left, 425 gms. Both lungs show scattered throughout small, hard encapsulated nodules, some with caseous centers, others completely fibrous. The majority of these are about the size of a pea, a few the size of a small bean. A moderate degree of congestion and œdema at the bases of both lungs. No acute inflammatory changes.

Blood-vessels without significant lesions.

No indication of thymus.

Liver.-Weight, I049 gms. Surface smooth and even. Section shows only a moderately congested appearance. Gallbladder of normal size, showing nothing notable.

Spleen.-Weight, I42 gms. Nothing of note.

Pancreas.-No abnormalities.

Kidneys.-Right, weight, I55 gms.; left, weight, I70 gms. Capsule rather adhesive, tearing cortex on removal. Surface a deep red. On section dark red cortex which is not thinned nor granular. Pyramids paler than cortex. Relationship cortex to medulla, I to 3.5 .

Urogenital system.-Bladder and urinary tracts normal. Uterus and ovaries moderately atrophied.

Gastrointestinal tract.-Enlargement of the intestinal lymph follicles. No changes in stomach.

Suprarenals.-Each gland weighed 145 gms. Both increased in size and adherent to adjacent organs. Surface nodular and misshapen; no normal parenchyma found. The glands are made up of dense, fibrous tissue enclosing areas of sticky semifluid, cheesy material, smears of which reveal the presence of tubercle bacilli.

Semilunar ganglia present no notable gross changes.

Head.-Brain, weight I 100 gms. Meninges very pale; vessels of pia empty; no evidence of inflammatory reaction. Cortex pale but everywhere normal in width. Section shows no gross anomalies.

Spinal cord shows no macroscopical changes.

Anatomical diagnosis.-Chronic fibrocaseous tuberculosis of suprarenal glands. Healed tuberculosis of lungs. Chronic pleuritis, adhesive. Moderate hypostasis. Bronzing of the skin. Cardiac hypoplasia. Small fenestration in aortic valve segment. Congestion of kidneys with beginning interstitial changes. 
Atrophy of ovaries and uterus. Hyperplasia of intestinal lymph follicles. Cerebral anemia.

Microscopical Examination.-Adrenals.-At the line of junction of the adrenal and the kidney a rich small-celled infiltration is found but no reaction within the kidney substance. The enlarged adrenals reveal only fibrous tissue surrounding areas of caseous degeneration. Nowhere was there any normal adrenal tissue.

Semilunar ganglia.-In neither semilunar ganglion is there any striking change. There is a brownish-yellow pigment in the cells which is not greater in amount than that found in the ganglia of patients of the same age. There are chronic inflammatory changes in the tissues surrounding the ganglia, but neither the fibrous increase nor the tubercular disease is discovered within the ganglia.

Spinal cord.-No degenerations with the Weigert-Pal or Marchi stains. The anterior horn cells show with the Nissl and eosin-methylene blue stain a pigment of a yellowish-brown color. All the cells are not equally pigmented. The extent of the pigmentation is not greater than the amount seen in senile conditions.

Cortex.-There is a very decided increase in the amount of pigment in the largest pyramidal cells. Some of the cells almost completely taken up with pigment. The pigmentation seen to a less degree in the smaller pyramidal cells. All extremes are seen, from the cell with a minute quantity to the balloon-shaped pigment sacs. Aside from the pigmentary changes the reaction in the cortex is confined to the nerve cells. The meninges are normal. No significant vascular changes. No neuroglia proliferation. The most usual cell change is a granular disintegration of the chromophile bodies, an elargement of the nucleus, deeplystained nucleolus, the non-stainable substance taking a pale stain. While in the majority of the cells the nucleus is round, in others it is irregular, and then the nuclear contents are deeply stained.

Pigmented skin.-The pigment is in the lower cells of the rete Malpighii, confined chiefly to the lowest layer but also found in the second lowest layer and rarely above. There are no prickle cells seen bearing pigment. Occasionally below the Malpighian layer there is a small patch of pigment but not within a cell. The 
pigment is confined almost exclusively to the cells. No pigmented connective-tissue cells.

The other microscopic changes may be briefly summarized as follows: Simple hyperplasia of the abdominal lymph glands; healed tubercular processes and passive hyperæmia in the lungs; slight muscular fiber atrophy with interstitial increase in the heart; healed foci of tuberculosis in the spleen; beginning interstitial changes in the kidneys.

Kiernan," in a paper on "Intertraction of Somatic and Psychic Disorder," writes: "Addison's Disease, when it complicates insanity, exerts a depressing influence on the patient's mental state." .... " It has not yet been demonstrated that Addison's Disease does more than complicate insanity. An etiological relationship is not yet established. Personally I am inclined to believe that Addison's Disease is secondary to the insanity it complicates in the great majority of cases."

Griesinger ${ }^{3}$ says that patients affected with it are profoundly depressed. The melancholic form with conditions of anxiety and emotion have been observed by Drs. Rutherford and McPhail.

Binswanger ${ }^{*}$ mentions condition of stupor, agitated confusion, and secondary dementia in connection with Addison's Disease, but states that the psychic disturbance is not clear.

The literature makes frequent mention of the existence of symptoms of coma, delirium, and convulsions, but reports of cases of prolonged mental disturbance in an otherwise uncomplicated Addison's Disease are exceptional.

Kellogg ${ }^{5}$ refers to a well-marked case of insanity with Addison's Disease, about which he says: "It is not improbable that there is some casual connection between the two affections."

There are various theories to explain the asthenia associated with Addison's Disease. Abelous and Langlois ${ }^{\circ}$ found that the extract of the muscles of an animal dying as a result of removal of the suprarenals possessed a toxicity similar to that of the muscles of an animal tetanized to exhaustion. They inferred that

Alienist \& Neurologist, Vol. 18, 1897.

'Hack Tuke's Dict. of Psychological Medicine.

- Lehrbuch der Psychiatrie, I904.

- Text-book of Mental Diseases.

- Arch. de Physiol., 1892, Vol. 4. 
3 I6 ADDISON'S DISEASE WITH TERMINAL MENTAL SYMPTOMS [Jan.

the muscular weakness following the removal of the suprarenals is due to toxic substances of a similar nature to those producing physiological fatigue, and that the functions of the adrenals is to supply antitoxic substances.

Lee' thinks it is more probable that the true explanation of the muscular asthenia in persons suffering from Addison's Disease is due to the absence of the normal tone-producing internal secretion of the bodies in question.

Whatever may be the true explanation of the asthenia in this disease, whether it is an autointoxication, which by some is considered the agent at work in all exhaustion psychoses and neuroses, or whether it is the absence of the normal secretion, it is to be expected that the central nervous system will react under certain conditions.

In this case, not until the factors contributing to the exhaustion had existed for some time were mental symptoms produced. An analysis of these symptoms shows a striking similarity to the known symptoms of cerebral exhaustion. The slight irritability, the diminution of the volitional impulses, the incapacity for mental application, the thinking disorder, and the sensory disturbances are indicative of a psychosis due to exhaustion. It is only fair then to assume that the mental disturbance in this case does bear an etiological relationship to the somatic disorder, and that we have an exhaustion or asthenic psychosis on the basis of Addison's Disease.

On the pathological side the findings would appear to confirm the original theory advanced by Addison, namely, that the disease depends upon the loss of function of the adrenals, the blood in consequence being poisoned by some material, the destruction or alteration of which is a function of these glands.

Lugaro in the Handbuch der Pathologischen Anatomie des Nervensystems, 1904, in his description of the changes in the sympathetic ganglia states: "Among the diseases which are considered as being associated with sympathetic diseases are Basedow's Addison's, and diabetes mellitus, but in all of these the pathological significance of the observed sympathetic lesions is very doubtful. . . .

"As it is known the most frequent and most important lesion in

'Frederic S. Lee, Fatigue. Journal A. M. A., May 19, 1906. 
Addison's Disease is found in the adrenals. In the great majority of the cases there occurs a tuberculosis of the adrenals which often presents caseous nodules. Instances of carcinoma and sarcoma are mentioned. In the sympathetic system the adjacent semilunar ganglia and the nerves of the solar plexus are the ones which are mostly affected. That this sympathetic disease is only secondary can be shown by many cases in which the semilunar ganglia and the nerves of the solar plexus do not show any important changes but in which there are changes in the adrenals" 